\title{
Editorial: 2003 - My predictions for revenue management
}

2003 (and beyond) will be a mixed year, with some parts of the world in recession and others not. Terrorism and war will strike (if they haven't already), plaguing government deficits and slimming corporate profits. But Wall Street will survive, even if a number of executives fall. Europe and China will be the places to be.

- The airlines' problems will come home to roost with at least two big US carriers folding. Capacity will be cut in dramatic fashion. But new airlines will emerge that are leaner and fitter. The business model has changed, and at least one new long-haul budget carrier will appear.

- By March, at least one budget carrier in Europe will fold, because of the price of oil. Airline prices long term will level out as consolidation in the budget carrier routes occurs.

- Charter flight companies will enter the budget business with limited routes.

- Lufthansa, BA and KLM will merge to become the largest airline in the world.

- The US government will no longer be able to bail out the US carriers.

- We will see a growth in cruise ships as a means of crossing the Atlantic, which will appear a safer way to travel.

- Revenue management will move from a forecasting model to a scenario planning model, in which numbers are not used but pictures painted.

- Revenue management will be used extensively in the retail trade as the science of pricing grows.

Journal of Revenue and Pricing Management, Vol. 1, No. 4, 2003

p. 300

(C) Henry Stewart Publications, 1477-657X
- All car purchases will be about the value chain, providing another opportunity for revenue management.
- Richard Branson will pull out of Virgin Atlantic.

- There will be a massive movement from 'hub and spoke' systems to 'point to point'.

- There will be greater use of revenue management in the online gaming industries. We will stay at home and play games on the Internet.

- Someone will make a lot of money exploiting how to use revenue management in a recession.

- We will go to the cinema more often and the cinema industry will take over airline revenue management as the main application.

- Revenue management will be used in the pharmaceutical industry to help manage AIDS.

- PROS RM will win the contract with the Russian Space Agency for the first generation of 'out of this world' RM software. It will even be mentioned in the next Bond film.

- When purchasing anything, customers will be given options on pricing. Revenue management will be about the value chain.

- Manchester United Football Club will become champions of revenue management. There will be a more aggressive link between sporting events and revenue management.

- Revenue management will make a big difference in 2003.

Happy New Year!
Ian Yeoman

Editor 